\title{
GA based Optimization of Control System Performance for Juice Clarifier of Sugar Mill
}

\section{SANDEEP KUMAR SUNORI', PRADEEP KUMAR JUNEJA², MAYANK CHATURVEDI ${ }^{2 *}$ and SOURABH BISHT ${ }^{2}$}

${ }^{1}$ Graphic Era Hill University, Bhimtal Campus, Uttarakhand, India.

${ }^{2}$ Graphic Era University, Dehradun, Uttarakhand, India.

*Corresponding author E-mail: mayankchaturvedi.geit@gmail.com

http://dx.doi.org/10.13005/ojc/320451

(Received: July 15, 2016; Accepted: August 11, 2016)

\begin{abstract}
In the present work, the $\mathrm{pH}$ neutralization system, which is a part of juice clarification process of sugar mill, is considered and control system is designed for it. Control systems based on ZN, IMC, LQG tuning are designed and their setpoint tracking performance is compared. The control system is further optimized to show an excellent performance using Genetic Algorithm (GA).
\end{abstract}

Keywords: Linear quadratic Gaussian; pH neutralization; setpoint tracking; genetic algorithm.

\section{INTRODUCTION}

This raw juice obtained from crushing mill contains some impurities hence it is sent to clarifier. In clarification process, the impurities are transformed to a thick paste of mud which settles down in the clarifier vessel. The clarification is done by adding milk of lime to the sucrose solution which neutralizes the $\mathrm{pH}$ value of solute on to 7 . It has been found that the critical parameters which can control the inversion of sucrose to glucose and fructose is the temperature and $\mathrm{pH}$ value of solution. The increase in temperature above room temperature speeds up the process of inversion.
Neutralization of $\mathrm{pH}$ value of sugar cane juice is a crucial task in the clarification of juice and it is a significant aspect which greatly affects the output quality of produced sugar. It is a complex, nonlinear, time varying and long time-delay process based on physical chemistry. The control of the $\mathrm{pH}$ value requires the manual adjustment in a real production industry, hence its control action is unsatisfactorily stable, i.e. sometimes $\mathrm{pH}$ value becomes extremely large and sometimes it is extremely small and the outcome is highly undesirable. The process flow diagram of the clarifier is presented in Figure 1.

\section{Genetic algorithm}

GA is inspired from the process of reproductions in living beings where the genes of 
the children are the outcome of the combination of genes of their parents. The steps of genetic algorithm are shown in form of flowchart in Figure 2.

The initiation of the GA is done with the selection of initial population of individual chromosomes. These chromosomes are the strings of genes and represent the possible solutions within the search space of the optimization problem. Each chromosome of the search space has a particular fitness value associated with it which is determine by the objective function. The more fit chromosomes are selected for mating to produce offspring.

The population is subjected to generations (number of iterations). New population is generated in each iteration by genetic operations such as selection, crossover and mutation. Fittest individuals get a chance to reproduce by crossover process by interchanging the fragments of their genetic information with other highly fit individuals. By this, new offspring solutions are produced which inherit some good characteristics acquired from both parents. After crossover the offspring are

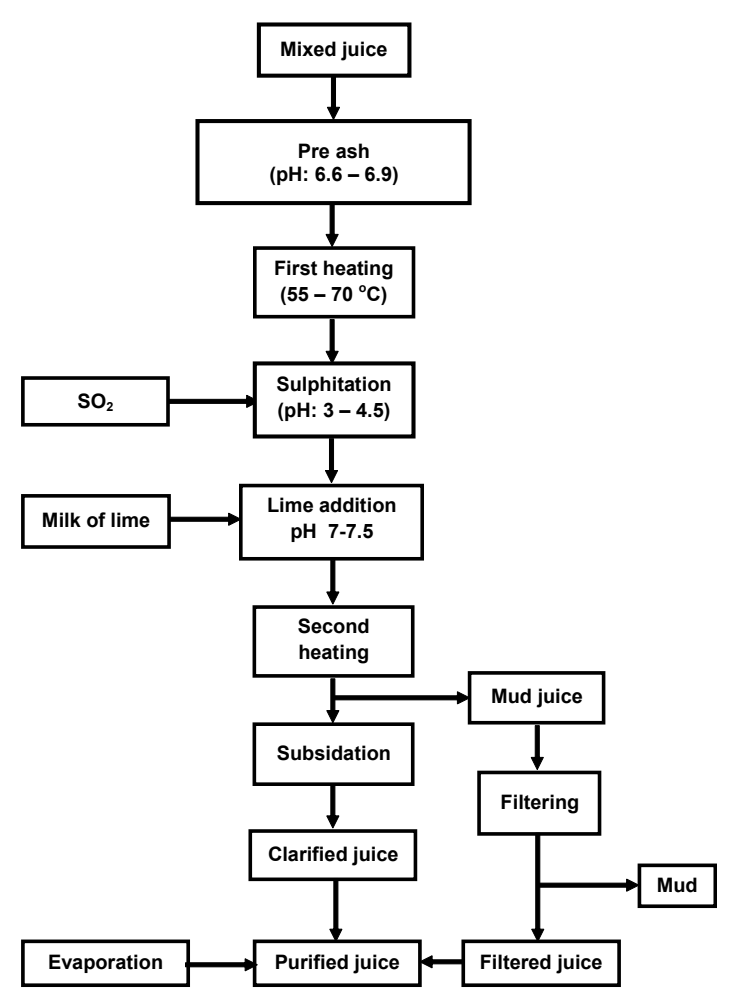

Fig. 1: Process flow diagram of juice clarifier ${ }^{1}$ subjected to mutation process where some genes of the chromosome strings are altered. The entire population or the less fit individuals are replaced by offspring produced.

The advantage of using GA over other optimization techniques is that GA can determine the global optimum solution without having any need to search for all solution spaces. Furthermore, the processing time only increases as the square of the project size and not exponentially.GA has been proven to be very robust algorithm in determining the optimum solution of verity of optimization problems very close to global minimum.

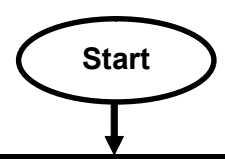

Generate initial population of solutions

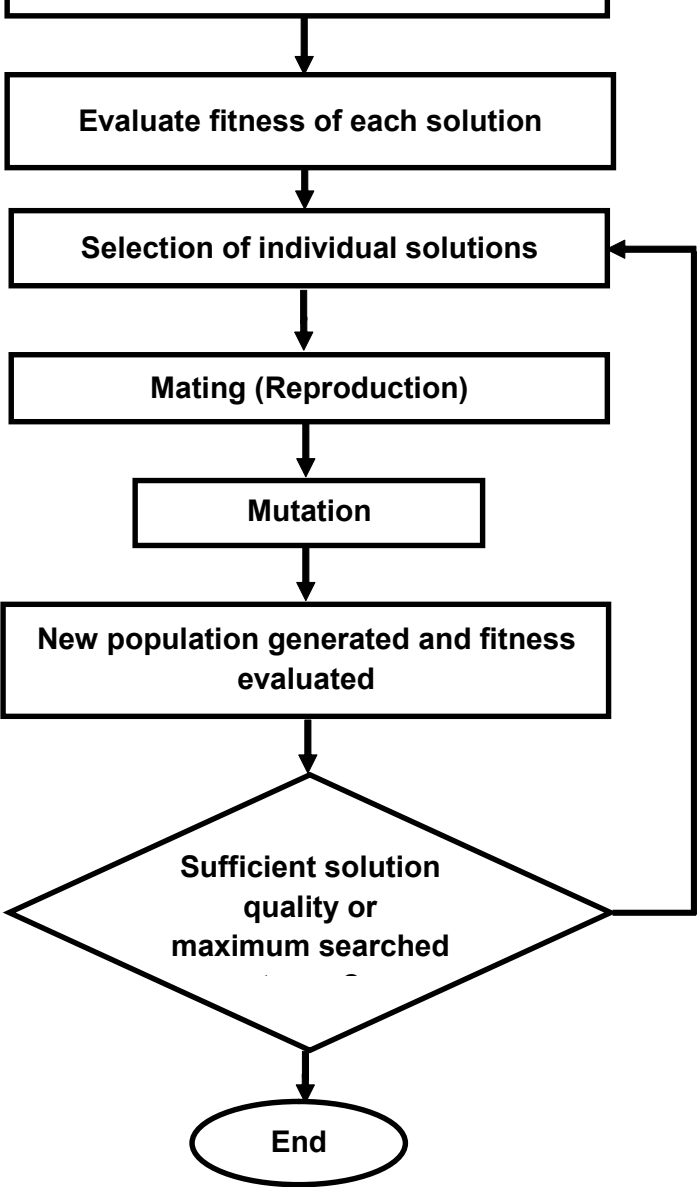

Fig. 2: Flow chart of genetic algorithm² 
Table 1: Performance parameters of designed controllers

\begin{tabular}{lccc}
\hline Controller & $\begin{array}{c}\text { Rise } \\
\text { time(s) }\end{array}$ & $\begin{array}{c}\text { Settling } \\
\text { time(s) }\end{array}$ & $\begin{array}{c}\text { Overshoot } \\
\text { (\%) }\end{array}$ \\
\hline ZN & 2.42 & 30.5 & 57.9 \\
IMC & 79.3 & 138 & 0 \\
LQG & 2.93 & 32.6 & 21.1 \\
GA & 1.61 & 21.5 & 9.8 \\
\hline
\end{tabular}

The transfer functions of the designed Ziegler-Nichols $(\mathrm{ZN})^{3}$, Internal Model Control

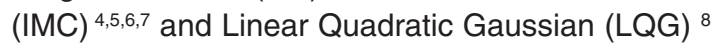
controllers for this are presented as equations (2), (3) and (4) respectively.

$$
C_{Z N}=\frac{13.054(1+5 s)}{s}
$$

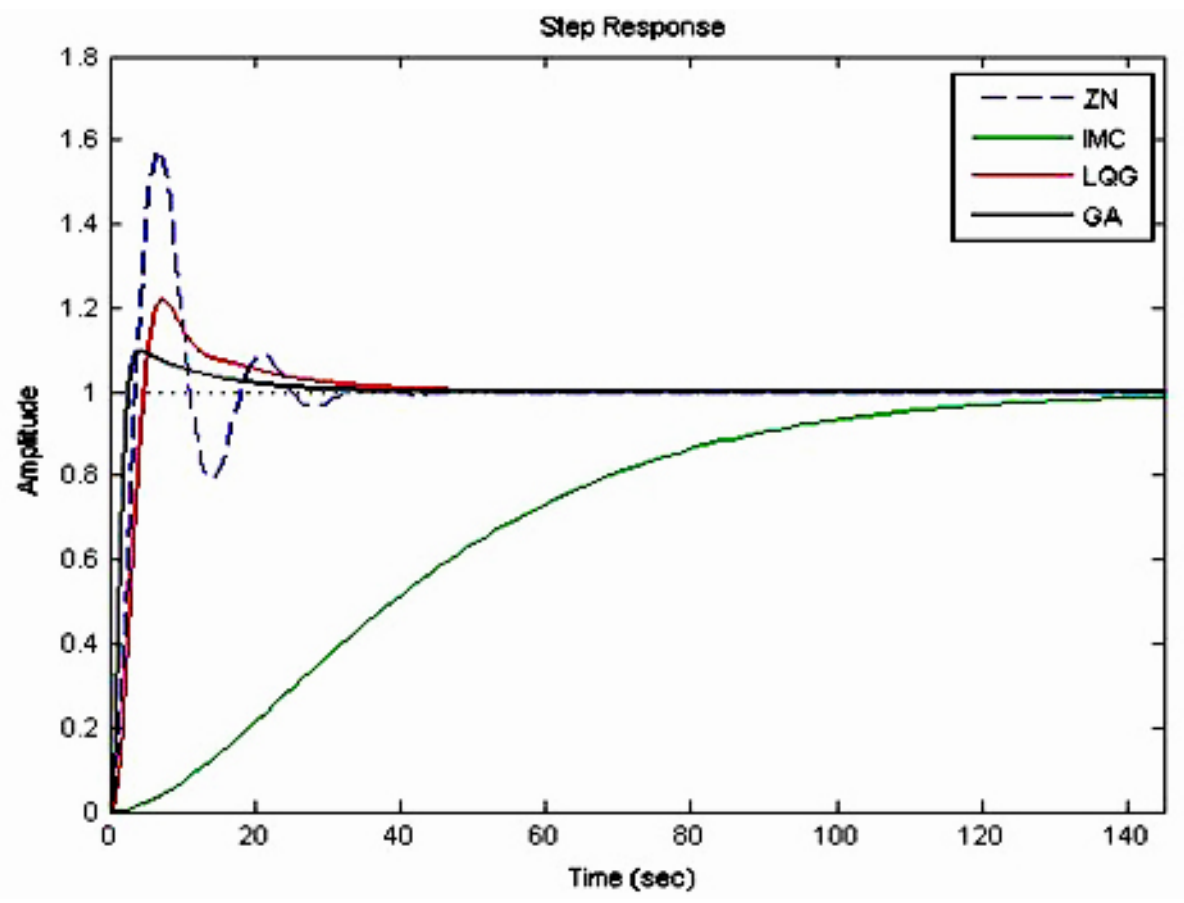

Fig. 3: Setpoint tracking responses of ZN, IMC, LQG and GA based controllers

\section{Control system design}

The transfer function model of the considered sugar clarifier ${ }^{1}$ is presented in equation (1).

$$
\mathrm{G}(\mathrm{s})=\frac{0.00416}{s^{2}+0.5083 s+0.00416}
$$

The input to this process is the lime feed and the output is the $\mathrm{pH}$ value of sucrose solution.

$$
C_{L Q G}=\frac{2.8817 \times(1+2 s)(1+15 s)}{s\left(1+1.4 s+(0.91 s)^{2}\right)}
$$

The above IMC controller has been designed with dominant closed loop time constant=23.6.

Now the above LQG controller is further optimized by running 100 iterations of GA in MATLAB. The transfer function of resulting controller is given in equation (5) 


$$
C_{G A}=\frac{7.076 \times(1+2 s)(1+12 s)}{s\left(1+0.55 s+(0.34 s)^{2}\right)}
$$

The setpoint tracking responses of these controllers are depicted in Figure 3.The corresponding performance parameters are specified in table 1.

\section{CONCLUSION}

In the present work, a SISO transfer function model of the $\mathrm{pH}$ neutralization process of juice clarifier found in the sugar mill has been taken from the available literature. First of all, ZN, IMC and LQG based controllers are designed for it. LQG controller's performance is found to be better than that of ZN and IMC with smallest settling time and small overshoot. Finally the performance of the designed LQG controller is further improved by GA optimization algorithm.

\section{REFERENCES}

1. Karthik, C.; Valarmathi. K; Prasanna, R.; Proceedings on International Conference on VLSI, Communications and Instrumentation, 2011, 24-28.

2. Nithya Rani N, Giriraj Kumar SM, Anantharaman N.; International Journal of Advanced Research in Electrical, Electronics and Instrumentation Engineering, 2013, 2(11), 5355-5364.

3. Ahmed H, Rajoriya A.; International Journal of u-and e-Service, Science and Technology, 2014, 7(5), 139-150.

4. Singh, R.; Bala, R.; Bhatia, B.; International
Journal of Advanced Research in Computer Science and Software Engineering, 2014, 4(6), 915-922.

5. Horn, IG; Arulandu, J.R.; Gombas, C. J.; VanAntwerp, J.G.; Braatz, R.D.; Industrial \& engineering chemistry research, 1996, 35(10), 3437-3441.

6. Scali, C.; Semino, D.; Morari, M.; Industrial \& engineering chemistry research, 1992, 31(8), 1920-1927.

7. Rivera, D. E.; and Flores, M. E.; Control Systems, Robotics and Automation, 2.

8. Eide, R.; Egelid, P.M.; Karimi, H.R.; Intelligent Control and Automation, 2011, I(02),160166. 